\title{
ENSINO DE FILOSOFIA PARA NÃO-FILÓSOFOS. FILOSOFIA DE OFÍCIO OU OFÍCIO DE PROFESSOR: OS LIMITES DO FILOSOFAR
}

\author{
Rodrigo Pelloso Gelamo*
}

\begin{abstract}
Eu jamais penso exatamente o mesmo pela razão de que meus livros são, para mim, experiências. Uma experiência é algo do qual a própria pessoa sai transformada. Se eu devesse escrever um livro para comunicar o que já penso, antes de haver começado a escrever, não teria jamais coragem de empreendê-lo. (Foucault, 1994, p. 41)

O E, “e... e... e...”, é exatamente a gagueira criadora, o uso estrangeiro da língua, em oposição a seu uso conforme e dominante fundado sobre o verbo ser. Certamente, o E é a diversidade, a multiplicidade, a destruição das identidades. (Deleuze, 1992, p. 60)
\end{abstract}

\begin{abstract}
RESUMO: O presente artigo é o resultado de um pensamento filosófico acerca do ensino de filosofia. O principal objetivo de nossa pesquisa foi entender o que faz o filósofo quando seu ofício é ser professor de filosofia. Para tal, utilizamos como referencial teórico-metodológico o pensamento de Foucault para pensar o filósofo-professor de filosofia em seu lócus - ensino de filosofia enquanto uma ontologia do presente, e o pensamento de Deleuze e Guattari para indicar uma possível maneira de entender esse ofício de professor que acreditamos se dar em um fazer artístico, filosófico e científico.
\end{abstract}

Palavras-chave: Ensino de filosofia. Ontologia do presente. Filosofia francesa contemporânea. Educação.

Mestre em Filosofia e doutorando pelo Programa de Pós-Graduação em Educação da Universidade Estadual Paulista (UNESP), de Marília. E-mail: gelamo@gmail.com 
Ensino de filosofia para não-filósofos. Filosofia de ofício ou ofício de professor...

PHILOSOPHY TEACHING FOR NON PHILOSOPHERS.

Philosophy OF OCCUPATION OR TEACHER'S OCCUPATION: THE LIMITS

OF PHILOSOPHIZING

ABSTRACT: This paper is the result of a philosophical thinking about philosophy teaching. The main goal of our research was to understand what philosophers do when their occupation is to teach philosophy. To do so, we used Foucault's thoughts as a theoretic-methodological framework to think the philosophersteachers of philosophy in their locus - philosophy teaching - as an ontology of the present, and Deleuze and Guattari's thoughts to point out a possible way to understand this teacher's occupation, which, we believe, happens in an artistic, philosophical and scientific manner.

Key words: Philosophy teaching. Ontology of present. Contemporary French philosophy. Education.

\section{Palavras iniciais}

$F$

omos motivados a pensar. Quando nos deparamos com uma disciplina estranha ao nosso modo de produzir pensamento, iniciamos uma problematização que resultou no texto ora apresentado. Vale deixar claro que estranho, aqui, refere-se a algo que não fazia parte de nosso rol de conhecimento filosófico. Este saber que chamamos de estranho, ou estrangeiro, é o ensino de filosofia. Melhor dizendo, uma tentativa de ensinar filosofia para estudantes de cursos que não pretendiam formar filósofos ou professores de filosofia. Assim, o limite que se colocava ao ensino de filosofia era o filosofar.

Este foi o problema que nos afetou de modo tal que nos fez sentir estrangeiros em nosso próprio país: era como se falássemos nossa língua materna e não fôssemos compreendidos. Problematizar esses afetos foi o que nos mobilizou, que nos desestabilizou, enfim, que nos fez pensar o problema do ensino de filosofia, do "ser" um filósofo/professor que problematiza seu processo de ensino.

Entendemos que este não seja um problema só nosso, mas de toda uma comunidade de pensadores que se dedicam à compreensão do ensino de filosofia. Esse tema vem sendo debatido amplamente pela comunidade filosófica na busca de entender o problema e propor en- 
caminhamentos para o ensino desse saber (Arantes, 1996). A ressonância desse estudo pode ser encontrada principalmente no Fórum Sul de Ensino de Filosofia, já em sua sexta edição, ${ }^{1}$ cujo resultado implicou uma coleção de livros sob o título Filosofia e ensino, publicada pela Editora UNijuí. No volume de 2004 (número 6), Pagni afirma que

Falar sobre o ensino de Filosofia não é uma tarefa tão simples, especialmente para aqueles que, como eu, por dever de ofício e por interesse em refletir sobre a própria atividade docente, há pouco tempo vêm pensando sobre o assunto (...). Com a recente reaproximação das discussôes em Filosofia da Educação, desenvolvidas no Brasil, de temas e do pensamento filosófico, sobretudo do pensamento contemporâneo e da História da Filosofia, o ensino dessa disciplina nos cursos superiores ganhou uma dimensão mais filosófica que pedagógica, sendo também interrogado pelas mesmas questôes que afligem o ensino de Filosofia. (Pagni, 2004, p. 217-218)

Acreditamos que pensar essa problemática se justifique não apenas por se tratar de um tema presente, conforme acentuou Pagni (2004), mas também pelo tratamento que vamos dar a ela por meio da base teórica deleuzo-guattariana e pelo modo de olhar o problema.

Com base nesse referencial, acreditamos poder produzir um modo diferenciado de entender nossa "prática filosófica" (ensino de filosofia), pensar nossa experiência educadora para entender como ela vem se constituindo e entender como o filósofo-professor de filosofia pode produzir pensamento, isto é, produzir filosofia, no processo educacional.

Para tanto, este artigo está dividido em três partes. A primeira delas tem a intenção de apresentar o problema que encontramos na sala de aula e mostrar como ele nos afetou. A segunda parte busca localizar nosso problema em um tipo de fazer filosófico nomeado por Foucault (1984) de ontologia do presente. Na última parte, visamos encontrar indicativos de caminhos na obra de Deleuze e Guattari para pensar o ensino de filosofia como filosofia, não se limitando a um saber técnico, mas se constituindo como um exercício do filosofar.

\section{A problemática do ensino de filosofia}

As questôes acerca do ensino - e especialmente do ensino de filosofia - surgiram com base em nossa experiência educadora em cursos de graduação, tanto de licenciaturas quanto de bacharelados, bem 
Ensino de filosofia para não-filósofos. Filosofia de ofício ou ofício de professor...

como da produção dos colegas de profissão, materializada nas ementas das disciplinas e no sentido que elas traziam. Nosso olhar foi marcado pela proposta de Pagni (2004), para quem "o professor dessa disciplina [filosofia] deveria refletir acerca de sua própria formação e dos limites de seu ofício" (p. 220).

Desde 2001, vimos trabalhando com o ensino de filosofia nos mais diversos campos do saber: Introdução à Filosofia, para os cursos de Jornalismo, Desenho Industrial, Licenciatura em Matemática, Pedagogia, Serviço Social e Análise de Sistemas; Filosofia e Ética Profissional, para os cursos de Administração, Ciências Contábeis e Informática; e Filosofia da Educação, para os cursos de Pedagogia e Licenciatura em Matemática. Nos cursos de Bacharelado e de Licenciatura em Filosofia, trabalhamos com as disciplinas de Ética e História da Filosofia.

Nossa experiência docente tornou-se cheia de contrastes. Cabe-nos desenvolver de que modo tais contrastes produziram as questôes que se tornaram problemas de nossa pesquisa. Nos cursos de filosofia, não tivemos problema quanto ao desejo dos alunos de aprender os conteúdos que eram próprios das respectivas disciplinas. Tivemos, entretanto, dificuldades no que se refere à adequação dos saberes adquiridos nos cursos de Prática de Ensino, durante nossa graduação, às necessidades que foram surgindo na experiência viva da sala de aula, ou seja, no ensino da filosofia.

No que concerne ao ensino de filosofia para os cursos que não visavam formar filósofos, a dificuldade apareceu de modo mais veemente. Os alunos, logo de início e de modo geral, não tinham o desejo de aprender os saberes ditos "filosóficos". Alguns, por experiências não muito agradáveis com outros professores de filosofia; outros, por mero descaso ou preconceito; outros, ainda, por influência dos primeiros. O que se tornava unânime era a questão: "o que isso (a filosofia) tem a ver com o curso que eu faço?”. Dito de outro modo, qual a relação existente entre a filosofia e os campos de saberes específicos para os quais cada um dos alunos estava sendo formado?

Essa foi a primeira questão que nos atacou, mas não foi a questão mais contundente. Outra dificuldade encontrada se deu com relação ao conteúdo apresentado nas ementas das disciplinas citadas. Todas elas nos direcionavam para um tipo de curso em que os alunos deveriam saber, ao seu término, um "resumo" da história do saber filosófico. Observa- 
mos aí um agravante: todas, com exceção da Filosofia da Educação, se constituíam como disciplinas que não dialogavam com os saberes que circulavam em outras disciplinas na formação dos alunos.

Ante o desprezo pela disciplina filosofia, que enxergávamos na maioria dos alunos, a ementa que materializava a proposta do curso permanecia intocada, inexorável e tecnicamente distante. Desse modo, o ponto de apoio para a resolução da questão anterior, ao invés de solucioná-la, criou uma outra: como propor uma discussão que fosse filosófica e mais próxima dos saberes para os quais os alunos estavam sendo formados se a ementa do curso não possibilitava realizar tal intento?

No caso da Filosofia da Educação, encontramos problemas parecidos, mas talvez outro plano estivesse se constituindo: a ementa poderia ser chamada de história de como os filósofos se referiram à educação. Não encontramos a possibilidade, sem que para isso tivéssemos que traí-la, de desenvolver o problema conceitual da educação, da filosofia, ou ainda, problematizar juntamente com os alunos os problemas educacionais sob o olhar da Filosofia. ${ }^{2}$ A questão mais uma vez foi colocada pelos alunos: qual a finalidade de saber história da filosofia da educação se eu vou ser um professor de matemática ou de educação infantil? Será que os saberes filosóficos podem contribuir apenas como um entendimento de como a história dos saberes filosóficos auxiliou a produção de cada saber específico e de como os filósofos pensaram este saber, neste caso, a educação?

A amplitude que a ementa alcançava era muito maior do que se poderia fazer em tão pouco tempo para desenvolver os conteúdos necessários para se entender o encadeamento das idéias filosófico-educacionais, fato que dificultava a assimilação pelos alunos, que nunca, ou muito pouco, haviam tido acesso ao saber filosófico.

Pensamos que os problemas não estejam localizados nos indícios aparentes, conforme apresentamos acima. Indícios da falta de preparo daqueles que formulam as ementas, daqueles que pensam as disposiçôes das disciplinas nas grades curriculares e, principalmente, daqueles que se aventuram a dar aula de filosofia, ou seja, na concepção de e no ensino de filosofia.

Pode ser que o problema esteja na ordem mais geral, na concepção mesma de ensino de filosofia. Lugar onde se deveria pensar qual o objetivo de uma disciplina estranha (no sentido que empregamos ante- 
Ensino de filosofia para não-filósofos. Filosofia de ofício ou ofício de professor...

riormente) a determinado campo do saber (no caso do ensino de filosofia para não-filósofos) e se entender qual seria a função do professor de filosofia (tanto para os cursos regulares de filosofia como para os de nãofilósofos). Que tipo de saber o professor deveria possuir e produzir? Que tipo de subjetividade ele auxilia a produzir/formar enquanto filósofo/professor? O problema, então, poderia ser colocado do seguinte modo: o que se espera do filósofo quando o assunto é ensino de filosofia?

Em meio a esses problemas - que poderiam ser entendidos como estando na ordem da empiricidade ou da técnica - fomos atacados por um problema que entendemos ser filosófico: o que faz o filósofo quando seu ofício é o ensino de filosofia? Este problema/experiência-de-pensamento mobiliza a contingência mesma do filósofo, vergando-o a pensar o próprio presente que se apresenta como problema. Problema que produziu, e produz em nós o desejo de pensar o que estamos fazendo de nós mesmos como educadores-filósofos. Problema que está localizado na ordem do acontecimento. Problema recorrente, insistente, na história do pensamento filosófico/educacional, que pode ser sintetizado no modo como Pagni (2004, p. 227) apresenta essa problemática: “(...) como os professores de filosofia poderiam filosofar para que o aprendiz também fosse despertado para tal, diante de uma situação em que a determinação da cultura só ampliou a deformação profissional daqueles e apenas auxiliou a sufocar a disposição destes para aprender a pensar criticamente o tempo presente?".

Vamos, na seção seguinte, buscar elementos que nos auxiliem a localizar nosso problema dentro das duas tradiçôes filosóficas descritas por Foucault (1984), a analítica da verdade e a ontologia do presente.

\section{Questão de método: a ontologia do presente}

Para pensarmos criticamente o tempo presente, ao qual se refere Pagni (2004), e no qual situamos nossa problemática, poderíamos buscar na literatura específica respostas acerca do ensino de filosofia. Contudo, queremos nos distanciar do modo "tradicional" do fazer filosófico e do saber filosófico/educacional. Queremos dar um tratamento novo ao problema. Novo aqui não deve ser entendido como novidade. Entendemos com Deleuze (1988, p. 225) que "O que estabelece o novo não é precisamente o novo, pois o próprio do novo, isto é, a diferença, é provocar no pensamento forças que não são as da recognição, nem hoje, nem 
amanhã, potências de um modelo totalmente distinto, numa terra incógnita nunca reconhecida, nem reconhecível”.

Por isso, optamos por não mais pensar o que é o ensino ou o que é o ensino de filosofia, mas por colocar a questão na ordem do acontecimento: o que faz o filósofo quando seu oficio é ensinar filosofia? Isso porque, conforme acentua Deleuze, "A filosofia está entulhada de discussōes sobre o juízo das atribuições (o céu é azul) e o juízo de existência (Deus é), suas reduções possíveis [o ensino de filosofia é ...] ou sua irredutibilidade [o ensino de filosofia não pode ser reduzido a ...]. Mas trata-se sempre do verbo ser" (1992, p. 59-60).

Não queremos, assim, buscar apenas elementos que concorram para explicar esses problemas que surgem de nossa experiência docente com base em outras experiências ou outras filosofias, mas buscar elementos conceituais que nos possibilitem pensar conceitualmente o problema. Esse modo novo de diagnosticar esses problemas encontramos nas obras de Foucault e Deleuze, especialmente na proposta de uma ontologia do presente foucaultiana e na crítica deleuziana acerca da imagem do pensamento.

Foucault, em sua vasta obra sobre a história e sobre o problema da subjetividade, dedicou-se, também, ao estudo de Kant. Nosso interesse específico nesse estudo de Foucault está em um artigo, O que é o iluminismo? (1984), no qual o autor analisa a obra Was ist Aufklärung? (1784) de Kant. Nesse artigo, Foucault indica que Kant foi o grande marco da modernidade. Segundo o autor, Kant parece

(...) ter fundado as duas grandes tradições críticas entre as quais está a filosofia moderna. Diríamos que em sua grande obra crítica Kant colocou, fundou, esta tradição da filosofia que coloca a questão das condiçôes sob as quais um conhecimento verdadeiro é possível e, a partir daí, pode-se dizer que toda uma parte da filosofia moderna desde o século XIX se apresentou, se desenvolveu como uma analítica da verdade. (Foucault, 1984, p. 111-112)

A segunda tradição à qual se refere Foucault é a ontologia do presente, ou analítica do presente. "A questão tem por objetivo o que é este presente, ela tem por objetivo inicial a determinação de um certo elemento do presente que se trata de reconhecer, de distinguir, de decifrar entre de todos os outros. O que é que, no presente, faz sentido para uma reflexão filosófica” (Foucault, 1984, p. 104). Vamos apresentar, a seguir, essas duas tradiçóes que surgiram com base em Kant. 
Ensino de filosofia para não-filósofos. Filosofia de ofício ou ofício de professor...

Com base na proposta metodológica kantiana, ${ }^{3}$ desenvolveu-se de maneira particular grande parte da pesquisa filosófica desde o século XIX. ${ }^{4}$ Foucault nomeia essa tradição de analítica da verdade por trazer, como principal preocupação, a determinação das condições do conhecimento para que este seja verdadeiro e se estabeleça como conhecimento científico. Esse traço metodológico é encontrado principalmente na filosofia analítica, em sua vertente formalista, e, de modo mais amplo, nas ciências neopositivistas, ambas cunhadas no paradigma cientificista fundado por Augusto Comte. Nas palavras de Kastrup (1999, p. 30-31), "O traço que os liga ao Kant da Crítica da razão pura é a preocupação em discutir e estabelecer as condições do conhecimento verdadeiro, por eles entendido como sinônimo de conhecimento científico. Comte trabalha com base na idéia de que só a ciência produz conhecimentos verdadeiros. Essa é, de resto, uma idéia kantiana (...)".

Trazendo esta discussão para o âmbito das relações entre a filosofia e a educação, a busca por verdades educacionais e por modelos que pudessem assegurar o verdadeiro ensino fez com que se criassem, nas pesquisas educacionais, inúmeros manuais para servir de modelo àqueles que se propusessem a pensar a educação, tendo como parâmetro os resultados esperados pela sociedade científico-filosófica de modo geral, e os critérios ortodoxos aos quais as pesquisas são submetidas. Segundo Bárcena (2005, p. 66), "a educação é entendida como um objeto de estudo ou conhecimento cietífico-tecnológico, um tipo de discurso que faz abstração do oral, do particular, do local e do temporal, para encaminhar-se à escritura científica, ao universal, ao geral e ao atemporal".

Esse modo de análise também foi utilizado para se pensar a educação que se pautou durante largo tempo, ainda que com exceções, na busca de critérios universais para encontrar aquilo que seria "verdadeiro" e "necessário" para produzir um caráter "científico" no pensamento educacional. Exemplos disso encontramos na seguinte passagem de Ghiraldelli Jr (2005, p. 10): "O tema da verdade é decisivo na filosofia da educação pela simples razão de que a noção de verdade está embutida, como pressuposto, em todo o universo do discurso educativo, pedagógico ou metapedagógico"; ou ainda, na passagem de Mazzotti (2000, p. 187), na qual critica o caráter universalizante da filosofia da educação em seu âmbito filosófico-racional “(...) o caráter da argumentação filosófica é apresentar-se como universalidade. Pode se dizer que a filosofia da educação só pode ser apresentada como tal caso se aceite 
alguma filosofia racional, a qual historicamente se apresenta no longo debate centrado no estabelecimento da universalidade".

Esses critérios científico-filosóficos da pesquisa educacional concordam com aquilo que Kastrup (1999, p. 33) entende como analítica da verdade: "A analítica da verdade estuda as representações e suas condiçōes, encontradas no domínio do sujeito, do método ou da linguagem. Para sustentar a representação, essas condições devem ser invariantes, universais e necessárias, à maneira da ciência".

A busca incessante pela verdade das/nas coisas e, principalmente pelos postulados feitos com base na obra de Kant, pela verdade analítica que se pode encontrar por meio de um método, fez com que o pensamento se dogmatizasse na tentativa de conhecer a verdade e descobrir a enunciação verdadeira das coisas. Desse modo, a vertente da analítica da verdade tem como princípio de reflexão o fato de que a verdade é algo que pode ser encontrado. Para Deleuze (1988, p. 218), "Esse elemento consiste somente na posição do pensamento como exercício natural de uma faculdade, no pressuposto de um pensamento como exercício natural, dotado para o verdadeiro, em afinidade com o verdadeiro, sob o duplo aspecto de uma boa vontade do pensador e de uma natureza reta do pensamento".

Deleuze criticou este modo de procedimento nomeado por ele, em Diferença e repetição, de Imagem do pensamento. Para ele a imagem do pensamento são os pressupostos encontrados tanto no senso comum quanto no pensamento filosófico. Deleuze aponta que o pensamento fundado na imagem do pensamento é problemático, uma vez que ela pode nos conduzir a pseudoproblemas.

Para Deleuze, a maneira como os pseudoproblemas são formulados já é uma tentativa de formulação-problema relacionada a uma resposta já elaborada e sabida, que, por sua vez, está ligada a uma imagem do pensamento. Os pseudoproblemas, assim, são concebidos segundo uma imagem do pensamento ligada a uma busca de valor de verdade em suas respostas. Em outras palavras, os pseudoproblemas são postulados que funcionam de tal forma a adequar os significados a significantes universais, a respostas já conhecidas. Este tipo de produção de conhecimento tenta encontrar nos significados e significantes convencionados uma maneira de representar um problema, de achar a representação de um problema que remeta aos significantes universais. Desse modo, os pseudoproblemas servem de pressuposto para o pensar. 
Ensino de filosofia para não-filósofos. Filosofia de ofício ou ofício de professor...

Nesse sentido, o pensamento conceitual filosófico tem como pressuposto implícito uma imagem do pensamento, pré-filosófica e natural, tirada do elemento puro do senso comum. Segundo esta imagem, o pensamento está em afinidade com o verdadeiro, possui fortemente o verdadeiro e quer materialmente o verdadeiro. (Deleuze, 1988, p. 218-219)

Para escapar dos pseudoproblemas colocados pela analítica da verdade/imagem dogmática do pensamento, faz-se necessário inventar um problema que problematize a contingência mesma do problematizador, no sentido de não buscar simplesmente um problema que já fora anteriormente colocado à moda dos pseudoproblemas, mas que corresponda ao movimento de produção de realidade imanente.

Para Foucault, este tipo de fazer filosófico, essa atitude filosófica, seria decorrente da segunda vertente que surge a partir do pensamento kantiano: a Ontologia do Presente. Segundo Foucault, a ontologia do presente trata de "mostrar em que e como o que fala enquanto pensador, enquanto sábio, enquanto filósofo faz parte, ele mesmo, desse processo e (mais que isso) como ele tem um certo papel a desempenhar neste processo, onde ele então se encontra então ao mesmo tempo como elemento e ator" (1984, p. 104).

Foucault (1984) afirma que esse modo de tratamento filosófico, esse método de análise, foi desenvolvido paralelamente ao da analítica da verdade por outros autores desde "Hegel à Escola de Frankfurt, passando por Nietzsche e Max Weber". Foucault assume que seu próprio método de trabalho e o que fundamenta sua obra é justamente a ontologia do presente, como ele mesmo afirma nas últimas palavras de seu artigo: essa é "uma forma de reflexão na qual tentei trabalhar" (1984, p. 112).

Esse método filosófico já está presente na obra de Foucault desde os anos 1960. Isso pode ser notado na resposta ao questionamento feito por P. Caruso sobre como ele classificaria sua obra. Foucault afirma que

É muito possível que meu trabalho tenha algo a ver com filosofia: sobretudo porque à filosofia - pelo menos desde Nietzsche - compete a tarefa do diagnosticar e não mais a de buscar dizer uma verdade que seja válida para todos e para todos os tempos. Eu procuro justamente diagnosticar: diagnosticar o presente. Eu procuro dizer aquilo que nós somos hoje e o que é que agora significa aquilo que nós dizemos. Este escavar sob os próprios pés caracteriza, desde Nietzsche, o moderno pensar e nesse sentido eu posso me designar como filósofo. (Foucault, 1994, p. 606, v.1) 
Parece-nos que o que Foucault quer entender é: "O que é precisamente este presente ao qual pertenço?" (1984), dito de outro modo, que tipo de filosofa estou fazendo e qual método estou utilizando para fazê-la? Esse modo de tratamento aos problemas se funda como um método, não porque está vinculado a um método no qual seu fundamento esteja na verdade sobre $o$ que deve ser pensado e sobre $o$ como determinada coisa deve ser pensada, mas a um presente que se apresenta como problema e que pede para ser pensado. Como um problema que pede uma solução.

A ontologia do presente se fundamenta, assim, em problemas muito precisos que "remetem diretamente a massa documental ou são perguntas que ele faz para seu próprio tempo, pois um problema somente é verdadeiro se formulado em função de uma clausura de condicionamento imanente que não vai além da experiência real" (Cardoso Junior, 2000, p. 89). O movimento de produção da ontologia do presente instala problemas na realidade e faz da realidade o seu problema. Desse modo, “(...) a ontologia do presente tem como condição de possibilidade uma diferença: detectar no presente, não a parte do ser, mas do devir, a parte inatual da realidade atual, a parte predominantemente importante" (Martins, 2000, p. 160).

Este modo de tratamento aos problemas filosóficos pode ser encontrado também em Nietzsche. Segundo Veiga-Neto (2003, p. 46),

A ontologia do presente é uma ontologia crítica de nós mesmos; ela desloca a questão (kantiana) para uma outra questão, também já presente em Kant, porém enfatizada por Nietzsche (...). Essa nova pergunta põe em relevo o sentido e o valor das coisas que acontecem conosco no nosso presente, não mais perguntando sobre a verdade das coisas - até porque a verdade para Nietzsche é histórica (...). Assim, a questão kantiana - que se pretendia transcendental - subordina-se à questão nietzscheana - que é contingente.

Nietzsche apresenta claramente seu projeto de crítica à modernidade, de crítica ao seu tempo, na obra Além do bem e do mal (2005). No parágrafo 58 , encontramos uma crítica contundente à indiferença dos filósofos em relação ao seu tempo e aos problemas que afetam o seu tempo (a falta de uma ontologia do presente).

Para Nietzsche, seu presente é marcado por um modo de fazer filosofia que busca "verdades objetivas" para se acreditar e tornar a vida mais fácil de ser vivida. Essa crítica pode ser encontrada principalmente no parágrafo 24 de Além do bem e do mal, onde se lê: 
Ensino de filosofia para não-filósofos. Filosofia de ofício ou ofício de professor...

O sancta simplicitas! Em que curiosa simplificação vive o homem! Impossível se maravilhar o bastante, quando se abrem os olhos para esse prodígio! Como tornamos tudo claro, livre, leve e simples à nossa volta! Como soubemos dar a nossos sentimentos um passe livre para tudo que é superficial, e a nosso pensamento um divino desejo de saltos caprichosos e pseudoconclusões!.

Este é o problema do presente de Nietzsche que ressoa em nosso presente: a santa simplificação das verdades, pseudoconclusões, enunciadas e assimiladas por todos de forma a tornar tudo claro, livre, leve e simples. Esta é a vontade de saber do homem contemporâneo: saber o que fazer para tornar sua vida simples. Dito de outro modo, saber como pode encontrar a verdade acerca das coisas para que possa seguir sem cometer erros e saber que está sendo correto em seu agir.

Nietzsche quer desestabilizar o pensamento acerca da Verdade e da possibilidade de se encontrar a essência das coisas. Uma das críticas a essa busca é feita com relação à possibilidade de se encontrar a verdade acerca da verdade sobre os valores de moralidade. Nietzsche, no parágrafo 108, afirma que "Não existem fenômenos morais, mas apenas uma interpretação moral dos fenômenos". Acreditamos que essa crítica possa ser potencializada e atribuída a toda a busca da verdade acerca do pensamento e da moralidade no que respeita à possibilidade de se dizer algo de verdadeiro, no sentido de ser universal e necessário, acerca das coisas que compreendem tanto o pensamento quanto a moralidade.

A pergunta que devemos nos fazer nesse momento é: como podemos escapar da analítica da verdade como método de fazer ciência e, particularmente em nosso caso, de fazer filosofia ou filosofia da educação? Parece-nos que nossa pergunta ressoa na de Foucault, na crítica de Nietzsche e, de modo mais remoto, em Kant, especificamente na maneira de colocar o problema de Was ist Aufklärung?, momento em que funda um modo diferenciado de fazer filosofia. Para Foucault (1984, p. 112),

(...) há na filosofia moderna e contemporânea um outro tipo de questão, um outro modo de interrogação crítica: é aquela que se vê nascer justamente na questão da Aufkärung ou no texto sobre a revolução; esta outra tradição crítica coloca a questão: o que é nossa atualidade? Qual é o campo atual das experiências possíveis?'. Não se trata da analítica da verdade, trata-se do que se poderia chamar uma ontologia do presente, uma ontologia de nós mesmos (...). 
Parece-nos que a proposta de Foucault, fundada em Kant e Nietzsche, é a de se fazer uma ontologia do presente. Procedimento este que consiste em pensar o próprio tempo com elementos contingentes, ou seja, não utilizar elementos de transcendência, sejam eles valorativos ou conceituais, para entender o que se passa com nós mesmos.

Este é o lugar em que situamos nossos problemas, enunciados na seção anterior. Fazer ontologia do presente é problematizar nossa contingência como elemento e como ator na relação cotidiana com o ensino de filosofia.

Olhar além do aparente. Talvez esta intenção, a insistência neste ponto, possa problematizar o fechamento da discussão sobre formação de professores. Entrar na lógica do sentido e não da formalidade na qual os discursos majoritários são desenvolvidos e funcionam para produzir o conceito tradicional de sistema educacional como único caminho de formação. Lógica fluida e imanente, encarregada de dar sustentação à transmissão da cultura legítima como herança. Para isso, temos que colocar o problema na ordem do acontecimento, fazer uma ontologia do presente. Não nos restringindo à ordem do dever ser reificado na estrutura de uma teleologia educacional, que tem como fim a Verdade. Entrar na espessura da realidade. (Gelamo \& Lima, 2006)

Seguindo a esteira enunciada por Foucault, esse problema somente poderia ser formulado da seguinte maneira: o que faz o filósofo quando seu ofício é ser professor de filosofia? Vale notar que nosso problema não é qual deve ser o conteúdo a ser ensinado?; o que é o professor de filosofia?; ou ainda, o que é o ensino de filosofia? Essas questôes nos levariam a pseudoproblemas e teríamos que propor pseudoconclusões, acreditando produzir verdades sobre isso.

\section{Ensino de filosofia como processo filosófico}

Uma vez colocado o problema e tendo-o situado na ordem filosófica da ontologia do presente, cabe-nos, se não resolver, ensaiar uma resposta. $\mathrm{O}$ caminho que encontramos para nos auxiliar nesse processo de pensamento foi o método filosófico desenvolvido por Deleuze e Guattari em $O$ que é a filosofia? (1997).

$\mathrm{Na}$ presente seção, partimos das seguintes hipóteses: (1) a de que o filósofo pode filosofar no exercício da docência; (2) pensamos que 
Ensino de filosofia para não-filósofos. Filosofia de ofício ou ofício de professor...

o ofício do professor de filosofia consista em filosofar, mas não se limite a isso; (3) ele deve produzir-se a si mesmo e criar condiçôes para que o ensino se efetive como um processo de subjetivação; (4) somente assim o ensino de filosofia pode se dar como um processo filosófico e produzir pensamento para alcançar as premissas que o saber filosófico impõe àqueles que querem fazer filosofia, ou seja, filosofar. Para responder a isso, fundamentamo-nos em Deleuze e Guattari, especialmente na obra $O$ que é a filosofia? (1997).

Entendemos que o filósofo-professor de filosofia precisa produzir seu plano de imanência para que possa entender o campo problemático que afeta seu presente. Este plano deve ser apresentado, a princípio, de modo intuitivo, como não poderia deixar de ser, e de modo consistente para que dê suporte à criação de seus conceitos. "O plano de imanência não é um conceito pensado nem pensável, mas a imagem do pensamento, a imagem que ele se dá do que significa pensar, fazer uso do pensamento, se orientar no pensamento (...)" (Deleuze \& Guattari, 1997, p. 53). Desse modo, o plano de imanência funciona como um mapa para que os conceitos filosóficos possam ser pensados no processo educacional.

Para Deleuze e Guattari (1997), "O plano [de imanência] é como um deserto que os conceitos povoam sem partilhar. São os conceitos mesmos que são as únicas regiões do plano, mas é o plano que é o único suporte do conceito" (p. 52). Por este motivo, o filósofo-professor tem antes que traçar o mapa do plano para criar os conceitos que o povoarão. É no plano de imanência que os conceitos serão enrolados e desenrolados, este é o lugar em que os conceitos podem funcionar (p. 51).

O plano de imanência é produzido pelas experiências de mundo formuladas com base nos modos de acesso à realidade. Assim, é o lugar no qual o filósofo problematiza e é problematizado pela realidade, fazendo com que ela se subjetive, se dobre, de determinado modo; lugar onde o pensamento é atacado, é o impensável não pensado. "O plano de imanência é como um recorte do caos e age como um crivo" (p. 59). Por esse motivo, segundo Deleuze e Guattari, ele é pré-filosófico, préconceitual. O plano de imanência é a matéria do pensamento. Matéria prévia na qual o pensamento se dobrará para produzir conceitos. Para Deleuze e Guattari (idem, p. 59), "O plano de imanência é pré-filosófico, e já não opera com conceitos, ele implica uma espécie de experimen- 
tação tateante, e seu traçado recorre a meios pouco confessáveis, pouco racionais e razoáveis. São meios da ordem do sonho, dos processos patológicos, das experiências esotéricas, da embriaguez ou do excesso".

Nosso plano de imanência foi produzido com base na problematização de nossas experiências tateantes: fomos problematizados pela nossa experiência docente, ou seja, pela contingência mesma do exercício filosófico do ensino de filosofia. Podemos indicar um caminho a seguir, pois, segundo Deleuze e Guattari, traçar um plano de imanência é traçar um recorte no caos. Assim, o problema ensino de filosofia penetra todas as outras questôes filosóficas em sala de aula e dá consistência para se pensar conceitualmente (1997, p. 60).

Partindo do plano de imanência, colocamos o problema que tensionou o plano. Inventamos um problema. Uma vez que não se deve simplesmente buscar um problema que já fora anteriormente colocado à moda dos pseudoproblemas, os quais não corresponderiam ao movimento de produção de realidade/plano de imanência, colocamos o problema na ordem do acontecimento: o que faz o filósofo quando seu ofício é ser professor de filosofia?

Ao instalar o problema na ordem do acontecimento, na ordem do presente, entendemos que o movimento de produção de realidade problematiza o plano de saberes que constituem a "aula" e, assim, exige solução. Para Deleuze e Guattari (1992, p. 27), a solução para os problemas em filosofia se dá por meio da criação de conceitos, por isso, "Todo conceito remete a um problema, a problemas sem os quais não teria sentido (...)". O conceito deve ser pensado como um momento de criação de sentido, um momento de produção de sentido, que foi exigido pelo movimento de produção, que constituiu seu plano de imanência problemático. Desse modo, é possível encontrar indícios que nos mostram o caminho para conceituar.

Nesse sentido, podemos criar conceitos que expressem os problemas do acontecimento da/na aula e testá-los para saber se esses são bons conceitos para fazer funcionar as intensidades problemáticas produtoras de vida educacional filosófica. Dito de outro modo, podemos problematizar os saberes que habitam o plano de imanência e entender como eles estão funcionando para expressar as produçōes do ensino de filosofia e de outros problemas que se constituem durante a atividade educacional. Desse modo, o educador filósofo pode agir e fazer o ensino 
Ensino de filosofia para não-filósofos. Filosofia de ofício ou ofício de professor...

de filosofia funcionar como produção de subjetividade, produzindo subjetivaçôes e fazendo com que o ensino de filosofia se torne um acontecimento filosófico, ou seja, uma criação de conceitos.

Este modo de pensar está em oposição ao modo da analítica da verdade de entender o sujeito do conhecimento, fundado na representação. Isso porque, se entendermos o sujeito como centro do processo, não poderemos pensar a criação de conceitos, uma vez que a representação se faz com base numa adequação do pensamento aos significantes representacionais. A criação supõe a reinvenção de signos e não a adequação do fluxo de pensamento aos significantes e significados estabelecidos. Por isso, precisamos pensar o ensino de filosofia como produção de subjetividade, com base em agenciamentos educacionais, como um processo de criação.

Se entendermos a aula como acontecimento filosófico, possibilitaremos que o processo educacional seja uma produção de subjetividade educacional filosófica que se dá como processo de subjetivação.

Um processo de subjetivação, isto é, uma produção de modo de existência, não pode se confundir com um sujeito, a menos que se destitua este de toda interioridade e mesmo de toda identidade. A subjetivação sequer tem a ver com a "pessoa": é uma individuação, particular ou coletiva, que caracteriza um acontecimento (uma hora do dia, um rio, um vento, uma vida...). É um modo intensivo e não um sujeito pessoal. É uma dimensão específica sem a qual não se poderia ultrapassar o saber nem resistir ao poder. (Deleuze, 1992, p. 123-124)

A idéia de Processo de Subjetivação foi pensada por Deleuze e Guattari em oposição aos conceitos tradicionais de sujeito e subjetividade, que, segundo nossos autores, não são bons conceitos para a compreensão do processo humano e de suas atividades cotidianas. Para esses autores, e neste caso incluiríamos também Foucault, "A subjetivação é a produção dos modos de existência ou estilos de vida” (Deleuze, 1992, p. 142); e não de um sujeito individual.

Esses autores entendem que a produção de um modo de existência não pode ser pensada como resultado da atividade cognitiva de um sujeito universal do cogito, entendido como uma individualidade que representa o mundo e que o sujeita à representação subjetiva de um indivíduo que tem primazia em relação a um objeto. Essa maneira de entender o sujeito é relativa a um $E u$, a um Você, a uma subjetivida- 
de individual ou individualizante do conhecimento, na busca de uma identificação do objeto conhecido como algo já dado, uma re-apresentação ao sujeito de uma imagem e, conseqüentemente, de um conhecimento pretendido como novo.

Retirando o ensino de filosofia da pseudo-pessoalidade da representação feita por um sujeito, podemos criar um campo de produção conceitual e transcendental em que o sujeito e o objeto, em que o ensinar e o aprender, sejam produzidos simultaneamente num Plano de Imanência. Para Deleuze, em Imanência: uma vida... (2002, p. 12), "A imanência absoluta existe em si-mesma: ela não existe em algo coisa, ela não é imanência $a$ algo, ela não depende de um objeto e não pertence a um sujeito". Já não haveria uma consciência detentora de um conhecimento pertencente a um sujeito.

Este modo de tratamento ao problema permite entender o que está sendo produzido pelo filósofo que se depara com o ofício do ensino de filosofia: entender que tipo de subjetividade a educação filosófica possibilita que seja instaurada, e qual a subjetividade que está efetivamente sendo instaurada pelas práticas sociais dos educadores filósofos.

A questão que se nos coloca nesse momento é: como fazer funcionar o ensino de filosofia no plano de imanência Educação e garantir o entendimento da produção de subjetividade e a criação de conceitos? Pensamos que a resposta para isso esteja no modo deleuzo-guattariano de entender o personagem conceitual. Para Deleuze e Guattari (1997, p. 105-106), "Se o conceito é uma solução, as condições do problema filosófico estão sobre o plano de imanência que ele supõe (a que movimento infinito ele remete na imagem do pensamento?) e as incógnitas do problema estão nos personagens conceituais que ele mobiliza (que personagem precisamente)".

Pensamos que quem tem maiores condições de mobilizar as incógnitas do problema seja o professor de filosofia e, assim, podemos entendê-lo como um personagem conceitual. O personagem conceitual nos possibilita a prática educativa do professor de filosofia que se depara com um plano de imanência, conforme apresentamos. " $\mathrm{Na}$ enunciação filosófica, não se faz algo dizendo, mas faz-se o movimento pensando-o, por intermédio de um personagem conceitual. Assim, os personagens conceituais são verdadeiros agentes de enunciação" (Deleuze \& Guattari, 1997, p. 87). O personagem conceitual entra 
Ensino de filosofia para não-filósofos. Filosofia de ofício ou ofício de professor...

no plano e faz funcionar os saberes que são próprios da filosofia em contato com zonas de impacto que não são propriamente produtoras, sabedoras ou sensíveis ao saber filosófico. Desse modo, entendemos que o professor de filosofia seja a condição de expressão no e do ensino de filosofia e contribua para a subjetivação do processo educacional.

Se o plano de imanência é, conforme apresentamos, pré-filosófico, o personagem conceitual é pró-filosófico. "Os personagens conceituais, em contrapartida, operam os movimentos que descrevem o plano de imanência do autor, e intervêm na própria criação de conceitos" (idem, ibid., p. 85). O personagem conceitual é o que vai viver a insistência dos conceitos no plano de imanência. Ele é quem vai fazer funcionar os conceitos.

\section{Outras considerações}

Entendemos, juntamente com Deleuze e Guattari, que a filosofia é o ato de pensar conceitualmente. "(...) ela [a filosofia] não é contemplação, nem reflexão, nem comunicação, mesmo se ela pôde acreditar ser ora uma, ora outra coisa, em razão da capacidade que toda disciplina tem de engendrar suas próprias ilusões, e de se esconder atrás de uma névoa que ela emite especialmente" (Deleuze \& Guattari, 1997, p. 14)

Pensamos que a ação em sala de aula do filósofo professor precise ser filosófica, no sentido de não apenas falar sobre os conceitos existentes e como eles se relacionam, fazendo oposição ou reafirmando os conceitos dados pela tradição filosófica. Este modo de proceder já era criticado por Deleuze em Conversaçôes: "Se ela mesma [a filosofia] nada cria, o que poderia fazer, senão falar sobre? Então reflete sobre o eterno, ou sobre o histórico, mas já não consegue ela própria fazer o movimento" (1992, p. 152).

Entendemos que nenhum conceito tem todos os elementos, todos os componentes (Deleuze \& Guattari, 1997, p. 27), por isso, um conceito deve ser criado, e é criado, pelos filósofos para expressar um plano conceitual em que está inserido. O professor filósofo deve criar um conceito que funcione. O que importa é fazer algo funcionar; se este algo - que pode ser um livro, um conceito, um pensamento - não funcionar, deve ser deixado. O problema deleuzo-guattariano é o funcio- 
namento: “(...) isso funciona, e como isso funciona?” (Deleuze, 1992, p. 16). Um conceito deve ser uma máquina que expresse o plano de imanência para o qual foi criado, e não que o represente.

O professor de filosofia deve fazer filosofia no sentido de se perguntar como os conceitos estão funcionando, “(...) o que nos importa é como uma coisa anda, funciona, qual é a máquina” (Deleuze, 1992, p. 33); testar os conceitos para saber quais deles funcionam e quais não funcionam para expressar nosso plano de imanência. Entender quais os conceitos que realmente estejam expressando o movimento de produção de realidade.

Pensamos que o personagem conceitual/professor de filosofia faça funcionar em sala de aula o saber filosófico como produção de conceitos. Acreditamos que, para que o ensino de filosofia se produza como um acontecimento, o professor de filosofia deve fazer filosofia. No sentido de que

A filosofia deve apresentar três elementos, cada um dos quais responda aos dois outros, mas deve ser considerado a si mesmo: o plano pré-filosófico que ela deve traçar (imanência), o ou os personagens conceituais que ela deve inventar e fazer viver (insistência) os conceitos que ela deve criar (consistência). (Idem, 1997, p. 101)

Desse modo, o ensino de filosofia poderia se dar como processo de subjetivação, como um modo de singularização de saberes dos/nos estudantes. Pensamos, assim, que o filósofo em seu ofício de professor de filosofia não possa fazer outra coisa a não ser filosofar.

Recebido em junho de 2006 e aprovado em setembro de 2006.

\section{Notas}

1. O Fórum Sul de Ensino de Filosofia é resultado da união de vários cursos de filosofia do sul do Brasil que se preocupam em debater o ensino de filosofia. Os encontros tiveram início em 2001 com o tema "Um olhar sobre o ensino da filosofia" e, a partir de então, foram realizados anualmente e discutiram os seguintes temas: "Filosofia e ensino em debate" (2002); "Filosofia e ensino: possibilidades e desafios" (2003); "Filosofia e ensino: um diálogo transdisciplinar" (2004); "Filosofia e Ensino: a filosofia na escola" (2005); e "Filosofia na Universidade" (2006).

2. Estamos tomando posição no que se refere ao tipo de filosofia que utilizaremos como fundamentação teórica, a saber: aquela que trata o saber como problema e como criação de 
Ensino de filosofia para não-filósofos. Filosofia de ofício ou ofício de professor...

conceitos. Entendemos que filósofos como Nietzsche, Adorno, Foucault, Deleuze e Guattari, dentre outros, tenham realizado este modo de fazer filosofia.

3. De modo geral, a problemática kantiana não é propriamente a verdade, mas os limites da razão. Kant quer entender quais são as condições e as possibilidades do uso da razão. Nesse sentido, argumenta, de um lado, contra o modo racionalista e, de outro, contra o modo empirista de entendimento do uso da razão. Segundo Deleuze, concordando com a leitura de Foucault, Kant (1986, p. 13) faz "Uma crítica imanente, a razão como juiz da razão, eis o princípio essencial do método transcendental. Esse método propõe-se determinar: 1 - A verdadeira natureza dos interesses ou fins da razão; 2 - Os meios de realizar esses interesses".

4. Vale ressaltar que, juntamente à analítica da verdade, desenvolveu-se, também, a ontologia do presente. Exemplo disso encontramos na filosofia de Nietzsche, conforme desenvolveremos a seguir.

\section{Referências bibliográficas}

ALLIEZ, E. (Org.). Gilles Deleuze: uma vida filosófica. São Paulo: Editora 34, 2000.

ARANTES, P. et al. A filosofia e seu ensino. Petrópolis: Vozes; São Paulo: EDUC, 1996.

BÁRCENA, F. La experiencia reflexiva en educación. Barcelona: Paidós, 2005.

CARDOSO JUNIOR, H.R. Deleuze leitor de Foucault: multiplicidades, ontologia, história em cofuncionamento no plano conceitual. Cadernos da F.F.C., Marília, v. 9, n. 1, p. 81-108, 2000.

DELEUZE, G. Para ler Kant. Rio de Janeiro: Francisco Alves, 1986.

DELEUZE, G. Diferença e repetição. Rio de janeiro: Graal, 1988.

DELEUZE, G. Foucault. São Paulo: Brasiliense, 1988.

DELEUZE, G. Conversaçôes. Rio de Janeiro: Editora 34, 1992.

DELEUZE, G. A imanência: uma vida... Educação \& Realidade, Porto Alegre, v. 27, n. 2, p.10-18, jul./dez. 2002.

DELEUZE, G.; GUATTARI, F. Mil platôs: capitalismo e esquizofrenia. Rio de Janeiro: Editora 34, 1996. 5v.

DELEUZE, G.; GUATTARI, F. O que é a filosofia? 2. ed. Rio de Janeiro: Editora 34, 1997. 
DELEUZE, G.; PARNET, C. Diálogos. São Paulo: Escuta, 1998.

EIZIRIK, M.F. Michel Foucault: um pensador do presente. 2. ed. Ijuí: UNIJUÍ, 2005.

FOUCAUlT, M. O que o iluminismo. In: Escobar, C.H. (Org.). Michel Foucault: o dossier. Rio de Janeiro: Taurus, 1984.

FOUCAULT, M. Dits et écrits: 1954-1988. Paris: Gallimard, 1994. 4v.

FOUCAULT, M. O que é a crítica? Cadernos da F.F.C., Marília, v. 9, n. 1, p. 169-189, 2000.

FOUCAULT, M. Omnes et singulatim: para uma crítica da razão política. Disponível em: <http://www.cfh.ufsc.br/ $\sim$ wfil/omnes.htm> Acesso em: 30 jan. 2006.

GALLO, S. O que é filosofia da educação?: anotações a partir de Deleuze e Guattari. Perspectiva, Florianópolis, v. 18, n. 34, p. 49-68, 2000.

GALLO. S. Deleuze e a educação. Belo Horizonte: Autêntica, 2003.

GALLO, S; DANELON, M; CORNELLI, G. Ensino de filosofia: ensino e prática. Ijuí: UNIJUÍ, 2004. p. 217-263.

GELAMO, R.P; LIMA, M.M. Notas (filosóficas) sobre o problema da formação de professores. Disponível em: <http://www.unb.br/fe/tef/filoesco/ resafe/index.php?Url=textos/artigos_rodrigoemarcia.html> Acesso em: 10 jan. 2006.

GROS, F. (Org.) Foucault: a coragem da verdade. São Paulo: Parábola, 2004.

GHIRALDELLI JUNIOR, P. A questão da filosofia e a filosofia da educação "em questão": verdade e discurso pedagógico na abertura do século XXI. In: Ghiraldelli Junior, P. Estilos em filosofia da educação. Rio de Janeiro: DP\&A, 2005. p. 9-23.

KANT, I. Que é o esclarecimento? (Aufkalärung) (1784). In: CARNEIRO LEÃO, E. (Org.). Immanuel Kant: textos seletos. Petrópolis: Vozes, 1985.

KANT, I. Crítica da razão pura. (1787). Lisboa: Fundação Kalouste Gulbenkian, 1989. 
Ensino de filosofia para não-filósofos. Filosofia de ofício ou ofício de professor...

KANT, I. O conflito das faculdades. (1789). Lisboa: Edições 70, 1993 KASTRUP, V. A invenção de si e do mundo: uma introdução do tempo e do coletivo no estudo da cognição. Campinas: Papirus, 1999.

KOHAN, W. Infância: entre filosofia e educação. Belo Horizonte: Autêntica, 2003.

MACHADO, R. Deleuze e a filosofia. Rio de Janeiro: Graal, 1990.

MARTINS, C.J. Michael Foucault: filosofia como diagnóstico do presente. Cadernos da F.F.C., Marília, v. 9, n. 1, p. 149-167, 2000.

MAZZOTTI, T.B. A filosofia da educação, uma outra filosofia? In: Guiraldelli Junior, P. O que é filosofia da educação? Rio de Janeiro: DP\&A, 2000. p. 185-204.

NIETZSCHE, F. Além do bem e do mal. São Paulo: Companhia de Bolso, 2005 .

PAGNI, P.A. Os limites e as discretas esperanças do ensino de filosofia: da questão da educação dos educadores aos temas reativos ao amor e à infância no pensamento contemporâneo. In: Gallo, S; Danelon, M; Cornelli, G. Ensino de filosofia: ensino e prática. Ijuí: UniJuí, 2004. p. 217-263.

RAGO, M.; ORLANDI, L.B.L.; VEIGA-NETO, A. (Org.). Imagens de Foucault e Deleuze: ressonâncias nietzscheanas. Rio de Janeiro: DP\&A, 2002.

VEIGA-NETO, A. Foucault e a educação. Belo Horizonte: Autêntica, 2003. 